\title{
Surgical management of a giant congenital left ventricular aneurysm in a 2-month-old infant.
}

Oleg Egunov ${ }^{1}$, Evgeniy Krivoshchekov², Frank Cetta ${ }^{3}$, Evgenii Sviazov ${ }^{2}$, and Alexander Sokolov ${ }^{2}$

${ }^{1}$ Tomsk NRMC Cardiology Research Institute

${ }^{2}$ FSBSI Tomsk National Research Medical Center of the Russian Academy of Sciences

${ }^{3}$ Mayo Clinic Minnesota

March 28, 2021

\begin{abstract}
This clinical case demonstrated surgical management of a giant congenital left ventricular aneurysm in a 2-month-old female using the Dor procedure. Transthoracic echocardiography performed at 6-month follow-up showed an ejection fraction of $66 \%$.
\end{abstract}

\section{Hosted file}

Case Aneurysm.pdf available at https://authorea.com/users/404477/articles/515644-surgicalmanagement-of-a-giant-congenital-left-ventricular-aneurysm-in-a-2-month-old-infant 
figures/Fig-1/Fig-1-eps-converted-to.pdf 
figures/Fig-2/Fig-2-eps-converted-to.pdf 